\title{
EFFECT OF A BONDING RESIN LAYER ASSOCIATED WITH A SELF-ETCHING ADHESIVE SYSTEM ON THE BOND STRENGTH OF INDIRECT RESTORATIONS
}

\author{
Carolina Guimarães CASTRO ${ }^{1}$, Paulo César Freitas SANTOS FILHO ${ }^{2}$, Adérito Soares da MOTA \\ Roberto Elias CAMPOS ${ }^{4}$, Carlos José SOARES ${ }^{4}$
}

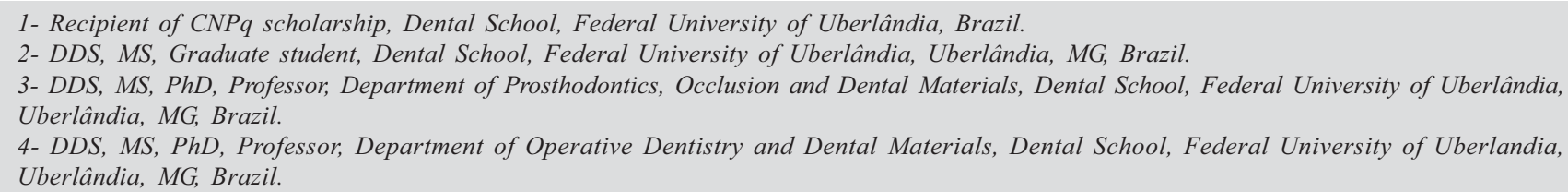

Corresponding address: Carlos José Soares - Faculdade de Odontologia - Universidade Federal de Uberlândia - Área de Dentística e Materiais Odontológicos - Av. Pará, nº 1720, Campus Umuarama, Bloco 2B, Sala 2B-24, 38405-902 - Uberlândia Minas Gerais - Brasil

Phone: 553432182255 - Fax; +55 3432182279 - e-mail: carlosjsoares@umuarama.ufu.br

Received: August 29, 2005 - Modification: July 18, 2006 - Accepted: March 13, 2007

\begin{abstract}
T

he aim of this study was to evaluate the influence of a low-viscosity bonding resin applied over a self-etching adhesive system on the microtensile bond strength ( $\mu$ TBS) of indirect restorations. Comparisons were made using One Up Bond F (OB) self-etching adhesive system, Single Bond (SB) one-bottle adhesive system and Scotchbond Multi Purpose Plus (SMP) bonding component. Thirty bovine incisors were extracted and decoronated at the cementoenamel junction. The labial surfaces were ground so that superficial dentin and deep dentin were exposed. The specimens were randomized to three groups $(\mathrm{n}=10)$ : G1- OB; G2- OB + SMP; G3- SB. In G2, a layer of the SMP bonding was applied over the OB adhesive system. Indirect composite restorations were bonded using dual-cure cement under $500 \mathrm{~g}$ load for $5 \mathrm{~min}$. The specimens were serially sectioned with a bonding area of $\pm 1.0 \mathrm{~mm}^{2}$ in 3 regions: enamel (E), superficial dentin (SD) and deep dentin (DD). The sticks were fixed with cyanoacrylate adhesive and submitted to $\mu$ TBS test at a crosshead speed of $0.5 \mathrm{~mm} / \mathrm{min}$ in a mechanical testing machine (EMIC DL 2000). The fractured specimens were examined under scanning electron microscopy to determine the failure mode. Data were analyzed by one-way ANOVA followed by Tukey's test $(\mathrm{p}<0.05)$. $\mu$ TBS means (in MPa) were: G1/E: $15.5 \pm 3.5 \mathrm{~b}$; G1/SD:

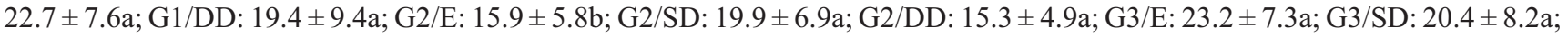
G3/DD: $19.1 \pm 8.7$ a. The results showed that the use of a low viscosity bonding resin did not affect the $\mu$ TBS means when associated with a self-etching adhesive system. The self-etching adhesive system was significantly more efficient in dentin than in enamel, while the one-bottle system was significantly more efficient in enamel when compared to the self-etching adhesive system.
\end{abstract}

Uniterms: Dentin-bonding agents; Microtensile test; Composite restorations.

\section{INTRODUCTION}

A stable adhesion between resin composite and tooth is essential for the clinical success of restorations and depends on an ideal interaction between the dental substrate and the adhesive system, resin cement and indirect restoration. A durable bonding to dentin is more difficult to achieve than to enamel due to its complex biological structures. The bonding mechanism of contemporary dentin bonding agents is based on the penetration of ambiphilic molecules into acid-etched dentin.

Self-etching adhesive systems have been recently introduced to the roll of restorative materials. As these bonding systems are applied directly to the smear-covered dentin, the acid etching step is eliminated ${ }^{16}$. The mild acidity of these materials is responsible for their inability to remove the smear plugs upon conditioning ${ }^{5}$. The acid conditioning primer dissolves and incorporates the smear layer, as it etches dentin and envelops the collagen fibrils and hydroxyapatite crystals ${ }^{12}$. It is assumed that no gap or voids exist because demineralization of the inorganic components and resin infiltration into the collagen fibrils occurs simultaneously to the same depth of demineralized dentin? ${ }^{7}$.

With the advent of contemporary self-etching adhesives, 
greater concentrations of acidic (ionic) resin monomers have been incorporated into the adhesives, which allow these materials to etch through the smear layer and demineralize the underlying intact dentin ${ }^{28}$. The incorporation of water and acidic monomers can affect negatively bond durability ${ }^{24}$ because a disadvantage of hydrophilic resin systems is that they attract water $^{21}$. The hydrophilic nature of these resins, therefore, enhances water sorption ${ }^{21}$.

Chemically activated composites that use tertiary amine as a component of the catalyst do not have a predictable bond with adhesives containing acidic resin monomers ${ }^{24}$. It is hypothesized that the tertiary amines in chemically activated composites are neutralized by the acidic resin monomers, losing their ability as reducing agents in redox reactions; thus, insufficient free radicals would be generated for an efficient polymerization ${ }^{9}$. Other factor responsible for compromising the bonding of self- or dual-cure composites to simplified adhesives is that adhesive that contains high concentrations of acidic resin monomers behave like permeable membranes ${ }^{23}$ and allow water movement from dentin to the composite-adhesive interface ${ }^{25}$

This apparent incompatibility relates to the fact that selfetching adhesives are used without an additional bonding resin layer ${ }^{24}$. Tay, et al. ${ }^{24}$ (2003) hypothesized that one solution to this problem would be to cover these hydrophilic adhesives with a hydrophobic adhesive (such as Scotchbond Multi Purpose). Thus, the aim of this study was to analyze the influence of a hydrophobic adhesive layer associated with a self-etching adhesive system on enamel and dentin microtensile bond strength. Bonding comparisons of self-etching and etchand-rinse adhesive systems were made for the different substrates.

\section{MATERIALAND METHODS}

Thirty bovine incisors were extracted decoronated at the cementoenamel junction. The labial surfaces were ground under water cooling in a mechanical grinder using 600-grit silicon carbide papers. Surfaces of enamel, superficial dentin and deep dentin were obtained with standardization of the smear layer. Specimens were fixed on an acrylic plate using cyanoacrylate adhesive (Super Bonder, Loctite, São Paulo, SP, Brazil) and wax, with parallelism between the prepared surfaces and the plate.

Resin composite blocks (TPH Spectrum; shade A3; Dentsply, Konstanz, Germany) were built using a silicone matrix (4 $\times 2 \times 7 \mathrm{~mm}$ ) with light polymerization of 40 seconds per increment using a light-curing unit with $600 \mathrm{~mW} / \mathrm{cm}^{2}$ output (XL 3000; 3M-ESPE, St. Paul, MN, USA). The polymerized composite blocks were sandblasted with $50-\mu \mathrm{m}$ particle aluminum oxide with 4 bar pressure (Microjet, Danville, CA, USA).

The teeth were randomized to 3 groups $(n=10)$ and the ground specimens of each group received a different treatment. Group 1 was treated with self-etching adhesive (One Up Bond F, Tokuyama Corp., Tokyo, Japan) with mixture and application of liquid A and B for 20 seconds and light curing for 10 seconds.
For Group 2, after the same treatment of Group 1, a hydrophobic adhesive layer (Scotchbond Multi Purpose bonding component, 3M/-ESPE, St. Paul, MN, USA) was applied over the self-etching adhesive previously used and light cured for 10 seconds. Group 3 was treated with $37 \%$ phosphoric acid for 15 seconds, rinsed for 15 seconds and gently dried with absorbent paper. Then, a first layer of one bottle adhesive (Single Bond, 3M-ESPE, St. Paul, MN, USA) was applied for 20 seconds, followed by a second layer and light curing for 10 seconds.

Resin composite blocks were then attached to the treated surfaces with dual cure resin cement (RelyX ARC, 3M-ESPE, St. Paul, MN, USA) under $500 \mathrm{~g}$ load for 5 minutes. Each side was light cured for 40 seconds.

The specimens were then serially sectioned in order to generate six sticks per tooth with a bonding area of about 1.0 $\mathrm{mm}^{2}$. Ten sticks encompassing each substrate (enamel, superficial and deep dentin) were selected under stereoscopic observation (40x) and fixed to a microtensile testing device with cyanoacrylate adhesive. The microtensile bond strength ( $\mu$ TBS ) of each stick was assessed in a testing machine (EMIC DL 2000, São José dos Pinhais, PR, Brazil) running at a crosshead speed of $0.5 \mathrm{~mm} / \mathrm{minute}$. After failure, the stick was removed from the testing apparatus and the cross-sectional area at the site of fracture was measured with a digital caliper (727, Starret Ind. Com. Ltda., Itu, SP, Brazil) to obtain values in MPa. The specimens were allowed to air-dry overnight, sputter-coated with gold and examined with a scanning electron microscope (LEO 435 VP; Carl Zeiss, Jena GmbH, Germany) to have their failure modes determined. $\mu \mathrm{TBS}$ means were expressed in MPa. Data presented a normal and homogeneous distribution, which allowed a parametric statistical analysis by one-way ANOVA followed by Tukey's test $(\alpha=0.05)$.

\section{RESULTS}

One-way ANOVA revealed statistically significant difference in the bond strength of the tested groups $(p<0.05)$. Table 1 summarizes $\mu$ TBS data for all groups analyzed by Tukey's test.

The application of a hydrophobic adhesive layer after selfetching adhesive system (Group 2) had no influence on $\mu$ TBS regardless of the substrate. Regarding enamel, statistically significant differences $(p<0.05)$ were found with higher $\mu$ TBS means for Group 3, in which etch-and-rinse technique was used. SEM observation showed that failures from this group involved typically cohesive fracture of the composite (Figure 1).

Regarding dentin substrate, there was no statistically significant difference $(p>0.05)$ among the groups even when superficial or deep dentin was considered. For groups G1 and $\mathrm{G} 2$, the most frequent mode of failure was mixed, involving composite indirect restoration, adhesive and dentin substrates (Figure 2). For specimens treated with one-bottle adhesive (G3), failures were partially adhesive between dentin and the adhesive layer, and partially cohesive of the adhesive layer (Figure 3). 


\section{DISCUSSION}

Due to evolution of preventive dentistry, it is difficult to obtain intact human teeth for laboratory studies. Therefore, human teeth have been currently substituted for bovine teeth ${ }^{18}$. Bovine teeth are more easily collected, make possible the standardization of age and reduce the risk of infectious

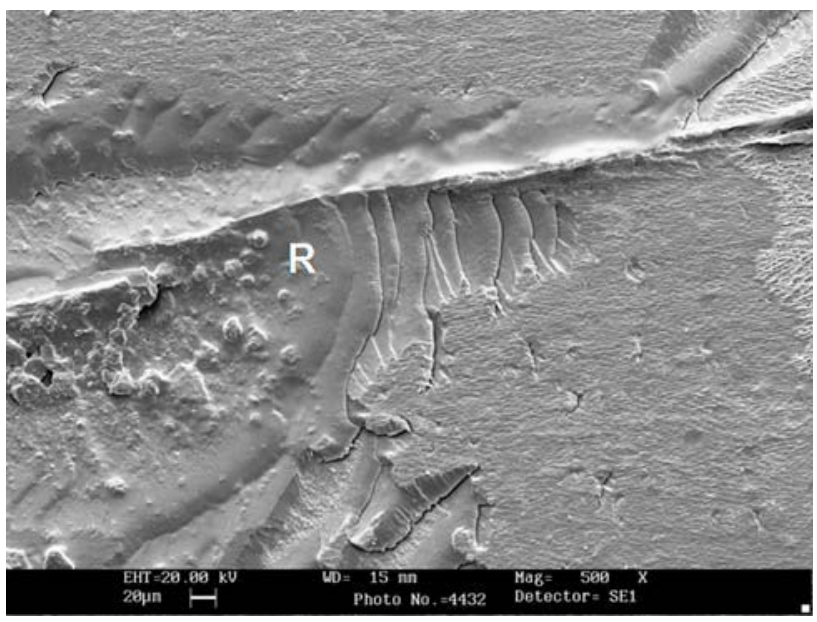

FIGURE 1- Failure in enamel of a specimen treated with total-etch adhesive system - Original magnification 500x ( $\mathrm{R}$ - restoration)

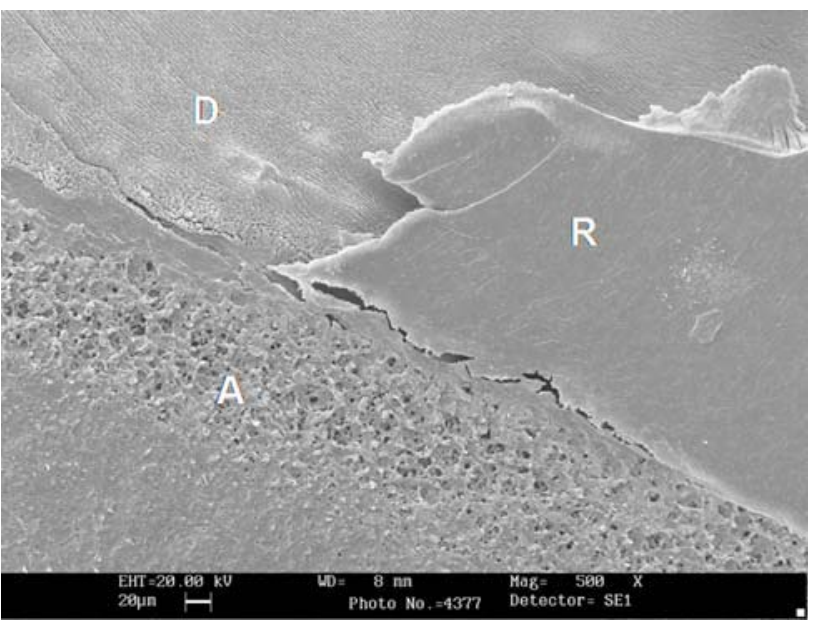

FIGURE 2- Failure in dentin of a specimen treated with selfetching adhesive system - Original magnification 500x ( $R$ - restoration; D - dentin; A - adhesive layer) disease transmission ${ }^{1}$.

According to Hayakawa, et al. ${ }^{8}$ (1998), the formulation of self-etching adhesive systems generally includes an aqueous mixture of acidic monomers, such as a phosphate ester or a carboxylic acid, and hydrophilic monomers, such as 2-hydroxyethyl methacrylate (HEMA), which is generally used at a concentration between 35 and 55 vol\% ${ }^{15}$. Eick, et al. ${ }^{3}$ (1993) observed that the addition of this monomer to primers used in dentin bonding has led to an increase in bond strengths. Due to their intrinsic acidity, self-etching systems can simultaneously etch and prime dental tissues, using the smear layer as an intermediate bonding substrate ${ }^{31}$.

Depending on the $\mathrm{pH}$, monomers exhibit different degrees of aggressiveness in their ability to demineralize subsurface intact dentin ${ }^{4}$. In this study, the self etching system theoretically presented an aggressiveness degree of demineralization due its low $\mathrm{pH}$ (1.2) resulting in high $\mu$ TBS means to dentin substrate, as observed when the conventional adhesive was applied ${ }^{27}$. When a self-etching primer/adhesive is applied to dentin, acidic primer/adhesive superficially etches through the smear layer and into the underlying mineralized dentin by partially dissolving mineral crystallites and simultaneously permitting monomer infiltration ${ }^{30}$. On the other hand, this acidity has been considered as a detrimental factor for restoration longevity. In simplified adhesives, uncured acidic monomers from the oxygen inhibition layer of the cured adhesives are in direct

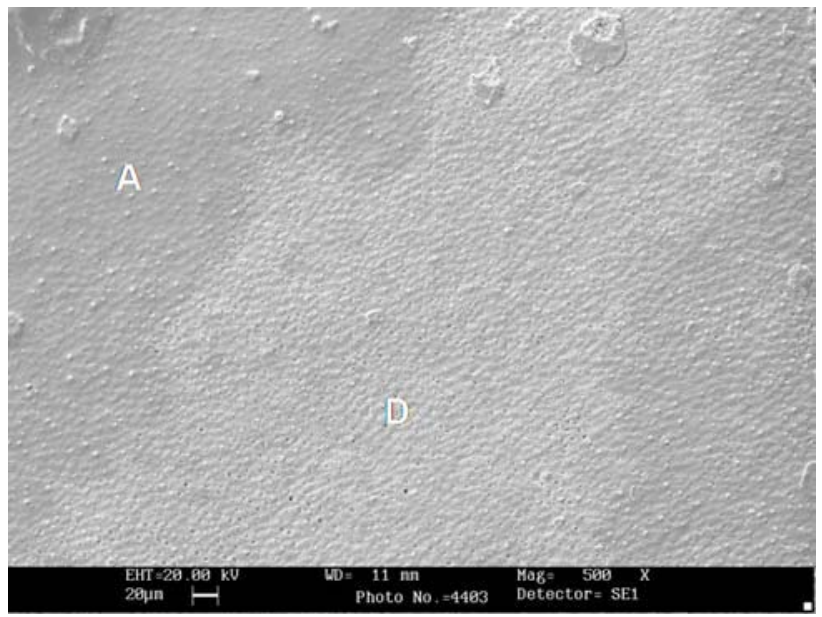

FIGURE 3- Failure in dentin of a specimen treated with total-etch adhesive system - Original magnification 500x (D - dentin; A - adhesive layer)

TABLE 1- Microtensile bond strength means (in MPA) ( \pm standard deviation) for the three groups

\begin{tabular}{llll}
\hline Group $(\mathbf{n}=10)$ & Enamel & Superficial dentin & Deep dentin \\
\hline G1 & $15.5(3.5) \mathrm{b}$ & $22.7(7.6) \mathrm{a}$ & $19.4(9.4) \mathrm{a}$ \\
G2 & $15.9(5.8) \mathrm{b}$ & $19.9(6.9) \mathrm{a}$ & $15.3(4.9) \mathrm{a}$ \\
G3 & $23.2(7.3) \mathrm{a}$ & $20.4(8.2) \mathrm{a}$ & $19.1(8.7) \mathrm{a}$ \\
\hline
\end{tabular}

Means followed by different letters indicate statistically significant difference at $5 \%$. 
contact with the resin composite ${ }^{20}$. The occurrence of an acid-based reaction between the acidic resin monomers in the adhesive, and the basic tertiary amine activator in the composite has been reported ${ }^{19}$, which can neutralize the basic amine ${ }^{20}$. The dissolved calcium and phosphorous ions, resulting from etching, osmotically attract water, which diffuses from the underlying dentin through the hydrophilic adhesive layer to create the water blisters ${ }^{13,24,25}$. Depending on the bonding substrates involved, acid-base reaction and adhesive permeability may contribute to the incompatibility between simplified-step adhesives and resin composites ${ }^{20}$. This phenomenon has been observed mainly with all-inone adhesives, such as One Up Bond $\mathrm{F}^{24}$. Similar finding has been reported with single step adhesives that behave as permeable membranes after polymerization ${ }^{22}$. Added to fluid filtration across bonded dentin, the presence of hydrophilic primer on some adhesives containing HEMA may adversely affect the polymerization of the resin monomers because monomer concentration rises after water evaporates from water-HEMA mixtures of primers, making it more difficult to remove residual water ${ }^{15}$. Thereby, these aspects can lower the thickness of the hybrid layer and its final mechanical properties ${ }^{15}$.

Although morphologic variations of dentin substrate have been reported ${ }^{6}$, stating that the intertubular dentin area and the adhesion quality are dependent on dentin region, no significant differences were found between $\mu$ TBS means in deep dentin and superficial dentin. Several studies have investigated the relationship between microstructure and the mechanical properties of dentin ${ }^{2,11}$. Differences in composition are thought to have strong effects on tensile strength $^{2}$. Furthermore, studies involving $\mu$ TBS tests commonly use samples of different dentin regions. This lack of standardization could result in a high standard deviation of the values.

On enamel, higher $\mu$ TBS means were found when the substrate was treated with Single Bond adhesive system (etch-and-rinse technique). At enamel-resin interface of specimens from this group (Figure 1), cohesive failure of the restoration was observed. Studies have reported that self-etching adhesives have lower bond strength to enamel than etch-and-rinse because phosphoric acid etched enamel has a roughened surface that increases micromechanical interlocking ${ }^{10,26}$. Additionally, the relative high concentration of hydrophobic monomers in Single Bond composition (manufacturer information) might also contribute to the high $\mu$ TBS of adhesive system to enamel.

SEM showed water blisters along the interface between dual-cured composite and One Up Bond F self-etching adhesive (Figure 2). These voids are formed by a process commonly known in the resin-coating industry as "osmotic blistering"17. The presence of HEMA, an ambiphilic molecule, in the composition of the bonding resin (Table 2) applied over the self-etching adhesive may be responsible for the nonsignificant difference in the $\mu$ TBS means. One of the modes of action of the HEMA-containing products is based on its ability to mix with water in interfibrillar spaces within the demineralized matrix ${ }^{14}$. According to this, if a pure hydrophobic compound, such as BisGMA, is used an increase in $\mu$ TBS could be hypothesized. Future studies should be conducted to confirm this hypothesis.

\section{CONCLUSIONS}

Within the limitations of the methodology used and according to the results of this study the following conclusions may be drawn:

- The application of bonding resin over self-etching adhesive layer had no influence on $\mu \mathrm{TBS}$, neither in enamel nor in dentin.

The use of an etch-and-rinse adhesive system resulted in significantly higher $\mu$ TBS means to enamel, and similar $\mu$ TBS means to dentin when compared to a selfetching adhesive system.

TABLE 2- Composition of adhesive materials and cement used in the study

\begin{tabular}{lll}
\hline Material & Brand name (Manufacturer) & Composition
\end{tabular}

Bonding resin

One-bottle adhesive system

Scotchbond Multi-Purpose (3M-ESPE)

Single Bond (3M-ESPE)

Self-etching adhesive system One Up Bond F (Tokuyama)

\author{
BisGMA, HEMA, photoinitiator \\ Water, ethanol, HEMA, BisGMA, DMA, \\ polyacrylic acid copolymer, photoinitiator, \\ itaconic acid \\ Water, MMA, HEMA, coumarin dye, \\ methacryloyloxyalkyl acid phosphate, \\ MAC-10, multifunctional methacrylic \\ monomer, fluoroaluminosilicate glass
}




\section{ACKNOWLEDGEMENTS}

The authors are indebted to Prof. EW Kitajima (NAP/ MEPA-ESALQ/USP) for technical support in scanning electron microscopy, to the FAPEMIG for financial support (Grants \# 159/04) and to the School Dentistry of Araraquara (UNESP) for assistance in the use of the serial sectioning machine.

\section{REFERENCES}

1- Brackett WW, Gunnin TD, Johnson WW, Conkin JE. Microleakage of light-cured glass-ionomer restorative materials. Quintessence Int. $1995 ; 26: 583-5$

2- Carvalho RM, Fernandes CAO, Villanueva R, Wang L, Pashley DH. Tensile strength of human dentin as a function of tubule orientation and density. J Adhes Dent. 2001;3:309-14.

3- Eick JD, Robinson SJ, Chappell R, Cobb CM, Spencer P. The dentinal surface: Its influence on dentinal adhesion. Part III Quintessance Int. 1993;24:571-82

4- Ferrari M, Davidson CL. Interdiffusion of a traditional glass ionomer cement into conditioned dentin. Am J Dent. 1997;10:295-7.

5- Frankenberger R, Perdigão J, Rosa BT, Lopes M. 'No-bottle' vs 'multi-bottle' dentin adhesives: a microtensile bond strength and morphological study. Dent Mater. 2001;17:373-80.

6- Garberoglio R, Brännström M. Scanning electron microscopic investigation of human dentinal tubules. Arch Oral Biol. 1976;21:35562 .

7- Gordan VV, Vargas MA, Cobb DS, Denehy GE. Evaluation of adhesive systems using acidic primers. Am J Dent. 1997;10:219-23.

8- Hayakawa T, Kikutake K, Nemoto K. Influence of self-etching primer treatment on the adhesion of resin composite to polished dentin and enamel. Dent Mater. 1998;14:99-105.

9- Ikemura K, Endo T. Effect on adhesion of new polymerization initiator systems comprising 5-monosubstituted barbituric acids, aromatic sulphonate amides, and tert-butyl peroxymaleic acid in dental adhesives resin. J Appl Polym Sci. 1999;72:1655-68.

10- Kanemura N, Sano H, Tagami J. Tensile bond strength to and SEM evaluation of ground and intact enamel surfaces. J Dent 1999;27(7):523-30.

11- Konishi N, Watanabe LG, Hilton JF, Marshall GW, Marshall SJ, Staininec M. Dentin shear strength: effect of distance from the pulp. Dent Mater. 2002;18:516-20.

12- Nishida K, Yamauchi J, Wada T, Hosoda H. Development of a new bonding system [abstract 267]. J Dent Res. 1993;72:137.

13- Nyunt MM, Imai Y. Adhesion to dentin with resin using sulfinic acid initiator system. Dent Mater J. 1996;15(2):175-82.

14- Pashley DH, Agee KA, Nakajima M, Tay FR, Carvalho RM Terada RS, et al. Solvent-induced dimensional changes in EDTAdemineralized dentin matrix. J Biomed Mater Res. 2001;56:273-81.

15- Pashley EL, Zhang Y, Lockwood PE, Rueggeberg FA, Pashley DH. Effects of HEMA on water evaporation from water-HEMA mixtures. Dent Mater. 1998;14:6-10.
16- Pashley DH, Carvalho RM. Dentin permeability and dentin adhesion. J Dent. 1997;25:355-72.

17- Pommersheim JM, Nguyen T. Prediction of blistering in coating systems. In: Bierwagen GP, editor. Proceedings of the American Chemical Society symposium series no. 689: organic coatings for corrosion control. Washington: American Chemical Society; 1998. p. $137-50$

18- Reis AF, Giannini M, Kavaguchi A, Soares CJ, Line SRP. Comparison of microtensile bond strength to enamel and dentin of human, bovine, and porcine teeth. J Adhes Dent. 2004;6:117-21.

19- Sanares AM, Itthagarun A, King NM, Tay FR, Pashley DH. Adverse surface interactions between one-bottle light-cured adhesives and chemical-cured composites. Dent Mater. 2001;17:542-56.

20- Suh BI, Feng L, Pashley DH, Tay FR. Factors contributing to the incompatibility between simplified-step adhesives and chemicallycured or dual-cured composites. Part III. Effect of acidic resin monomers. J Adhes Dent. 2003;5(4):267-82.

21- Tanaka J, Ishikawa K, Yatani H, Yamashita A, Suzuki K. Correlation of dentin bond durability with water absorption of bonding layer. Dent Mater J. 1999;18(1):11-8.

22- Tay FR, Pashley DH, Suh BI, Carvalho RM, Itthagarun A. Singlestep adhesives are permeable membranes. J Dent. 2002;30(7-8):37182

23- Tay FR, Pashley DH, Yiu CK, Sanares AM, Wei SH. Factors contributing to the incompatibility between simplified-step adhesives and self-cured or dual-cured composites. Part I. Single step self-etch adhesive. J Adhes Dent. 2003;5:27-40.

24- Tay FR, Pashley DH. Have dentin adhesive become too hydrophilic? J Can Dent Assoc. 2003;69:726-31.

25- Tay FR, Pashley DH. Water treeing: a potential mechanism for degradation of dentin adhesives. Am J Dent. 2003;16:6-12.

26- Torii Y, Itou K, Nishitani Y, Yoshiyama M, Ishikawa K, Suzuki $\mathrm{K}$. Effect of self-etching primer containing $\mathrm{N}$-acryloyl aspartic acid on enamel adhesion. Dent Mater. 2003;19(4):253-8.

27- Van Meerbeek B, De Munck J, Yoshida Y, Inoue S, Vargas M, Vijay P, et al. Buonocore memorial lecture. Adhesion to enamel and dentin: current status and future challenges. Oper Dent. $2003 ; 28(3): 215-35$

28- Van Meerbeek B, Vargas M, Inoue S, Yoshida Y, Peumans M, Lambrechts $\mathrm{P}$, et al. Adhesives and cements to promote preservation dentistry. Oper Dent. 2001;(Suppl 6):119-44.

29- Van Meerbeek B, Yoshida Y, Snauwaert J, Hellemans L, Lambrechts P, Vanherle G, et al. Hybridization effectiveness of two step versus a three step smear layer removing adhesive system examined correlatively by TEM and AFM. J Adhes Dent. 1999;1:723

30- Wang Y, Spencer P. Physicochemical interactions at the interfaces between self-etch adhesive systems and dentine. J Dent. 2004;32:56779

31- Watanabe I, Nakabayashi N, Pashley DH. Bonding to ground dentin by phenyl-P self-etching primer. J Dent Res. 1994;73:121220 . 